\title{
Uso de terapia de vacío en el Hospital Infantil La Fe de Valencia [España]: experiencia y resultados
}

\section{Experience and results with the use of vacuum assisted therapy at the children's Hospital La Fe, Valencia [Spain]}

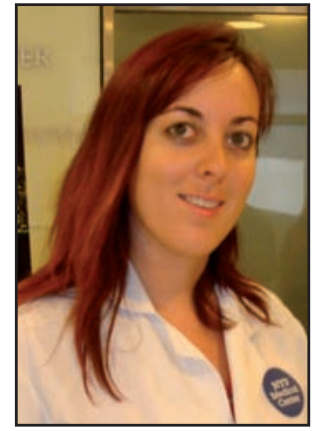

Lorca García, C.

Lorca García, C.*, Pérez García, A.*, Hortelano Otero, A.*, Centeno Silva, J.A.*, López Blanco, E. ${ }^{\star *}$, Gutiérrez Ontalvilla, P. **, Pérez Plaza, A.*, Klenner Muñoz, C.*

\section{Resumen}

El uso de la terapia de vacío en el tratamiento de heridas complejas y de evolución tórpida tiene sus inicios en los años cuarenta. Sin embargo, la experiencia con su utilización en la población infantil es mucho más reciente. En la actualidad no disponemos de estudios científicos contrastados y con nivel de evidencia A para emitir conclusiones firmes en estos casos; a pesar de ello, la experiencia clínica acumulada hasta el momento es satisfactoria en la mayoría de los casos.

En la gestión sanitaria moderna, el control de recursos y costes es hoy en día un pilar fundamental; es por ello que contar con una terapia de estas características constituye un recurso de gran valor, sobre todo cuando la intención es minimizar la estancia hospitalaria y a la vez mejorar la calidad de vida del paciente, lo cual es especialmente importante cuando se trata de niños.

Presentamos la experiencia en el uso de terapia de vacío en pacientes pediátricos del Servicio de Cirugía Plástica y Reconstructiva del Hospital La Fe de Valencia, España, entre los años 2007 y 2010.

\author{
Palabras clave Heridas, Terapia de vacío, \\ Terapia de presión negativa, \\ Pacientes pediátricos.
}

Código numérico 15117-1526
Key words Wounds, Vacuum assisted therapy, Negative pression therapy, Paediatric patients.

Numeral Code 15117-1526 


\section{Introducción}

La presencia de heridas crónicas y agudas en la población adulta ha recibido mucha atención por parte de la comunidad sanitaria durante los últimos años, dada su elevada prevalencia y el gasto sanitario que suponen. No obstante, la presencia de este tipo de lesiones en la población pediátrica no ha recibido la misma dedicación, bien por su menor prevalencia o por el menor número de especialistas que se dedican a ello.

Las causas más frecuentes de úlceras en la infancia son dermoabrasiones, extravasaciones, heridas quirúrgicas con evolución tórpida, dermatitis asociadas a incontinencia, quemaduras químicas y térmicas, heridas secundarias a malformaciones congénitas y úlceras por presión (1).

Existen multitud de apósitos y presentaciones farmacológicas para tratar este tipo de lesiones, todas ellas con un interés común: conseguir un cierre rápido de las heridas, con menor disconfort para el paciente y con la mejor gestión posible de los recursos sanitarios $(1,2)$.

La terapia de vacío se ha convertido en una herramienta útil en el tratamiento de heridas agudas, crónicas o de tórpida evolución (2). No obstante, los estudios sobre la acción de la presión negativa en los tejidos se han realizado de modo experimental en animales y en la población adulta, pero existe poco conocimiento al respecto en la población pediátrica. Es más, hasta el momento, que nosotros sepamos, no se ha publicado ningún estudio randomizado del manejo de esta herramienta de tratamiento en la población pediátrica y la única base de la que se dispone actualmente, son estudios retrospectivos y de descripción de casos, así como la extrapolación de resultados de estudios en adultos y, obviamente, la propia experiencia clínica de los médicos que la emplean.

El objetivo de este trabajo es mostrar nuestra experiencia en el uso de la terapia de vacío en la población pediátrica en el Hospital Infantil La Fe de Valencia, España, entre los años 2007 y 2010.

\section{Material y método}

Presentamos una serie de casos clínicos tratados en nuestro Servicio, en los que la terapia de vacío ha supuesto una herramienta fundamental para el tratamiento de diversas heridas en pacientes pediátricos. En todos ellos, la terapia de vacío usada ha sido el sistema VAC® (Vacuum Assisted Closure, KCI Clinic Spain SL).

\section{Caso 1.}

\section{Terapia de vacío en dehiscencia de esternotomía}

Varón de 18 días de vida que presenta dehiscencia de esternotomía y signos de mediastinitis al $4^{\circ}$ día de postoperatorio tras cirugía cardiaca para tratamiento de transposición de grandes vasos, ductus arterioso persistente y comunicación interauricular. Realizamos cultivo de la he- rida, que se confirma como negativo. Tras lavado y retirada de esfacelos y fibrina, realizamos cura oclusiva con apósito de plata. Asímismo, en la Unidad de Cuidados Intensivos neonatales (UCIN) se inicia tratamiento antibiótico (ATB) profiláctico con Vancomicina y Ceftazidima. Al día siguiente se observa salida de material seropurulento a través de la herida, aunque tras una nueva limpieza se comprueba que el esternón es viable y no hay signos clínicos de infección. Se decide instaurar terapia VAC® a $-75 \mathrm{mmHg}$ en modo continuo con esponja de poliuretano.

A los 3 días realizamos la primera cura, observando disminución de esfacelos, fibrina y exudado. Seguimos realizando cambios de sistema VAC $®$ cada 3 días y al $9^{\circ}$ de terapia volvemos a tomar cultivo de la herida, siendo el resultado en este momento positivo para Staphylococcus coagulasa negativo, Enterococcus y Enterobacter. Dichos microorganismos eran sensibles a la terapia antimicrobiana que se estaba administrando, por lo que no hubo necesidad de modificar el tratamiento.

La terapia de vacío se mantuvo durante 17 días y al retirarla, el lecho de la herida presentaba un tejido de granulación sano, por lo que se pasó a realizar curas planas diarias. Pasados 3 días más, el paciente fue dado de alta hospitalaria. Se revisó en consultas externas al mes del alta, observando curación completa.

\section{Caso 2.}

Terapia de vacío en amputación de falanges distales de pie

Mujer de 18 días de vida que presenta necrosis de dedos de pie derecho tras trombosis y vasoespasmo de la arteria iliaca derecha. Como antecedentes cabe destacar: prematuridad $(27+4)$, ductus arterioso persistente, comunicación interauricular y enfermedad de la membrana hialina. Desde el momento del nacimiento presentó palidez de pierna derecha y pérdida del pulso pedio. Ante la sospecha de trombosis, se inició tratamiento por cateterismo umbilical con heparinas de bajo peso molecular y anti X-a. Al no mejorar el estado de la extremidad, se realizó eco-doppler que confirmó trombosis y vasoespasmo de la arteria iliaca derecha. Es en este momento cuando se realiza interconsulta a nuestro Servicio ( $5^{\circ}$ día de vida) y se comienza cobertura antibiótica con Vancomicina y Ceftazidima, según protocolo de UCIN

Dado el aspecto de los dedos del pie, procedemos a exploración quirúrgica bajo anestesia general que confirma necrosis de falanges distales de los 5 dedos del pie derecho, por lo que procedemos a la amputación de las mismas y dejamos cura oclusiva con apósito húmedo y colagenasa. El cultivo de la muestra dio como resultando positivo para Corynebacterium spp sensible a los antibióticos que se estaban usando.

Debido a los signos inflamatorios y al abundante exudado de la herida, a la semana de la intervención decidimos instaurar terapia de vacío mediante sistema VAC® con esponja de poliuretano a $-30 \mathrm{mmHg}$ en modo contí- 
nuo. Realizamos curas cada 48 horas y a los 4 días se retiró el sistema ya que conseguimos disminuir los signos inflamatorios, el edema y la exudación de la herida; además, apareció un tejido de granulación limpio que permitió pasar a una pauta de tratamiento con curas ambulatorias, realizando curas en el centro de salud cada 3 días y revisando la herida en consulta externa de nuestro hospital cada 2 semanas. A los 40 días de postoperatorio la herida estaba totalmente epitelizada sin que la paciente haya requerido una nueva intervención quirúrgica.

\section{Caso 3.}

\section{Terapia de vacío en dehiscencia de laparotomía}

Mujer de 3 meses de vida por la que se realiza interconsulta a nuestro Servicio debido a la aparición de una dehiscencia de laparatomía. Entre sus antecedentes clínicos destacamos: prematuridad $(25+1)$, ductus arterioso persistente, ectasia piélica bilateral, y enfermedad de la membrana hialina. A la semana de nacimiento comienza a presentar distensión abdominal y no deposiciones. Se inicia tratamiento conservador, pero debido al empeoramiento del cuadro abdominal, se interviene quirúrgicamente realizándose laparotomía exploradora que descubre una perforación de íleon distal que se reseca en cuña y se cierra. A los 15 días de la intervención, aparece un exudado purulento a través de la herida quirúrgica que se cultiva y da un resultado positivo para Cándida chabrata. Se procede a tratamiento tópico con antifúngicos.

El proceso abdominal no se resuelve, por lo que se vuelve a intervenir quirúrgicamente a los 7 días; esta vez se observa enterocolitis necrotizante que lleva a una resección de ciego y colon ascendente e ileostomía de descarga. Al mes de dicha intervención aparece una fístula estercorácea que se interviene nuevamente, realizándose resección y anastomosis ileo-cólica término-terminal. A la semana de esta última intervención vuelve a aparecer una dehiscencia de la herida quirúrgica que se trata con curas planas hasta que la paciente es remitida a nuestro Servicio.

Tras limpieza de la herida, procedemos a instaurar terapia VAC® a $-50 \mathrm{mmHg}$ en modo continuo con esponja de poliuretano, realizando curas cada 5 días. La paciente siguió el tratamiento antibiótico pautado en la UCIN. La terapia de vacío se mantuvo 11 días, tras los cuales la herida presentaba un aspecto sano y limpio. Se realizaron curas con tul y Nitrofurazona durante aproximadamente 2 semanas más, tras las cuales, la herida epitelizó totalmente.

\section{Caso 4.}

\section{Terapia de vacío en dehiscencia de laparotomía complicada}

Varón de 4 meses de vida que es remitido a nuestro Servicio con dehiscencia de laparotomía complicada con fístula enterocutánea (Fig. 1). Como antecedentes clínicos presenta: prematuridad (24 s); intervención quirúr-

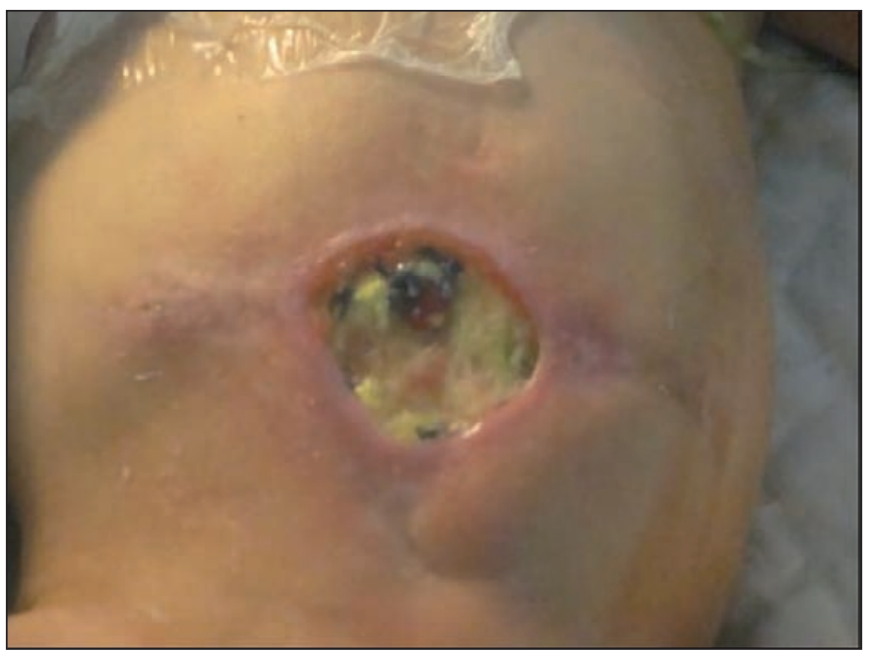

Fig. 1. Dehiscencia de laparotomía con fístula enterocutánea.

gica a los 23 días de vida por enterocolitis necrotizante, en la que se encuentra vólvulo de divertículo de Meckel y perforación intestinal, por lo que se realiza resección de aproximadamente $30 \mathrm{~cm}$ de intestino delgado; a los 13 días de dicha intervención se reinterviene quirúrgicamente por falta de efectividad de la anastomosis y obstrucción intestinal, realizándose adhesiolisis y resección de íleon. A los 15 días de la intervención aparece una fístula enterocutánea que motiva una reintervención quirúrgica correctora 7 días más tarde, realizándose resección y anastomosis término-terminal. Una semana después de esta última reintervención, es cuando se avisa a nuestro Servicio por la aparición de una dehiscencia de laparotomía y recidiva de la fístula.

En el momento de esta consulta, el tratamiento de la fístula por parte de Cirugía Pediátrica era expectante, por lo que se opta por realizar un tratamiento conservador con apósitos absorbentes hasta que el Servicio responsable del paciente decidiera un tratamiento definitivo. Pasados 3 días de curas, y dado el hecho de que Cirugía Pediátrica mantenía la decisión de tratamiento expectante, decidimos colocar un sistema VAC ${ }^{\circledR}$ con esponja de polivinilo a $-50 \mathrm{mmHg}$ en modo continuo según técnica de la seta (Fig. 2).

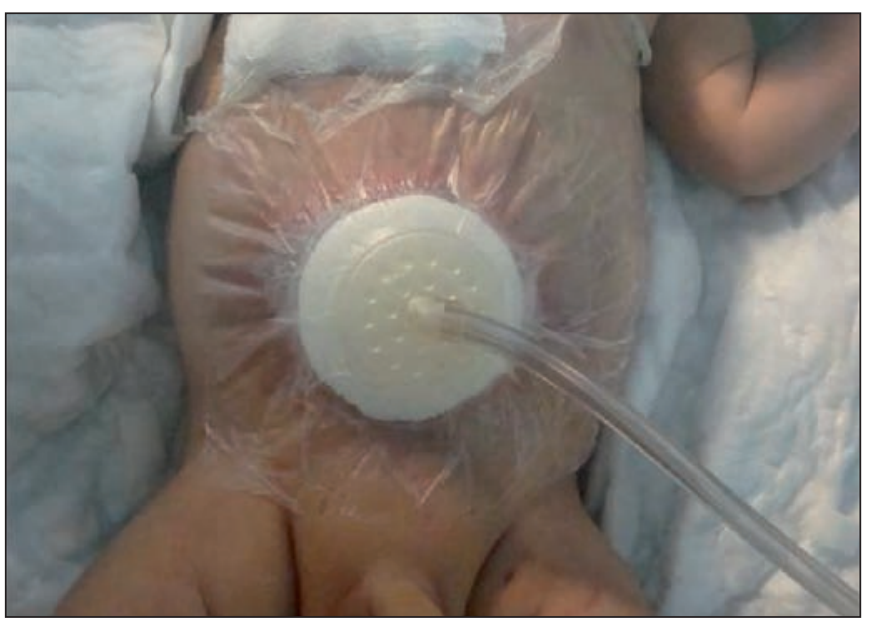

Fig. 2. Sistema VAC $®$ con esponja de polivinilo (técnica de la seta). 
Las curas se realizan a demanda, según el exudado de la herida, cada 3-5 días; comprobamos disminución del débito de la fístula y buena evolución de la dehiscencia, apareciendo islotes de epitelización (Fig. 3,4). En todo momento, el paciente estuvo en tratamiento con somatostatina y nutrición parenteral total (NPT), así como con antibioticoterapia con Vancomicina y Ceftazidima. A los 15 días de tratamiento con terapia de vacío y dada la buena evolución experimentada, decidimos suspender la somatostatina y reintroducir la nutrición enteral; con ello, el débito de la fístula aumenta de $0{ }^{\prime} 5 \mathrm{cc} / \mathrm{h}$ a $2 \mathrm{cc} / \mathrm{h}$, por lo que volvemos al tratamiento inicial con NPT y somatostatina hasta la resolución completa de la fístula. A los 25 días de tratamiento con terapia de vacío, tanto el débito como la pérdida de sustancia habían disminuido: de 2 a 1' $1 \mathrm{cc} / \mathrm{h}$ y de $4 \times 3 \mathrm{~cm}$ a $3 \times 2 \mathrm{~cm}$, respectivamente (Fig. 5). Al mes de tratamiento, no se observa ya salida de líquido ni orificio fistuloso y la pérdida de sustancia es mínima, por lo que se decide retirar el sistema VAC® (Fig. 6).

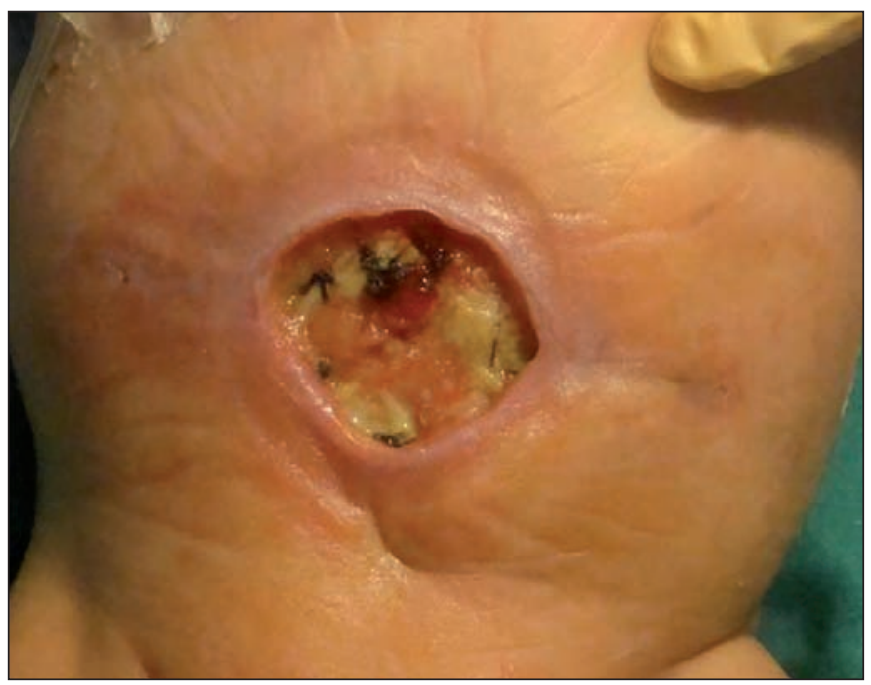

Fig. 3. Primera cura tras la colocación del sistema VAC $®$

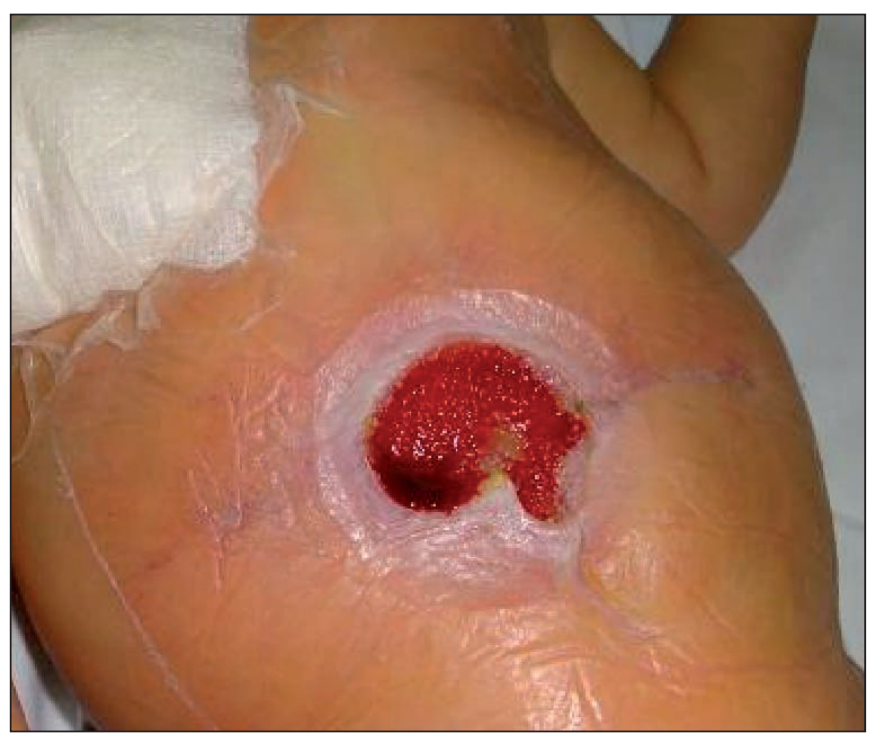

Fig. 4. Tejido de granulación sano con bordes en proceso de epitelización.

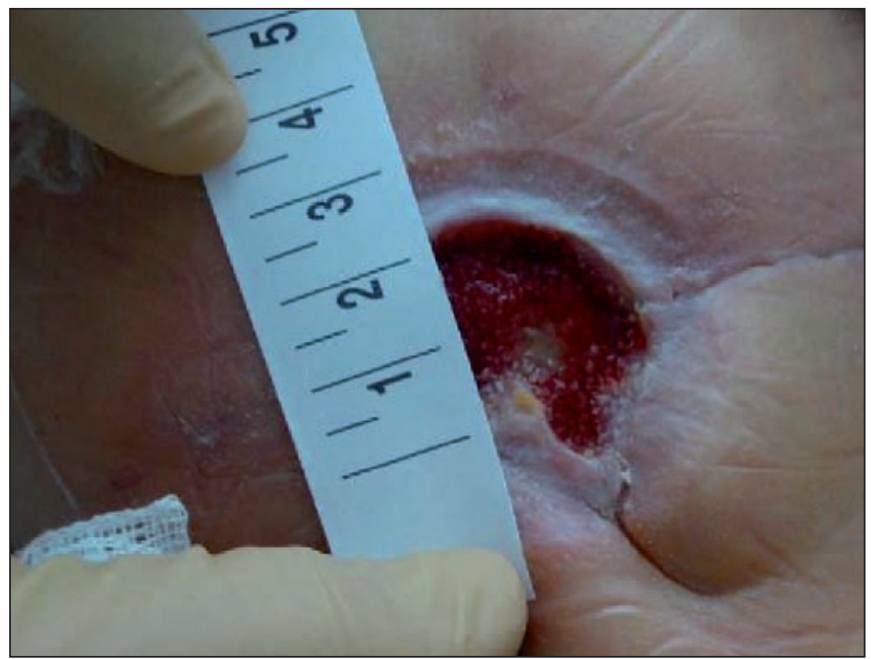

Fig. 5. Disminución del tamaño de la dehiscencia.

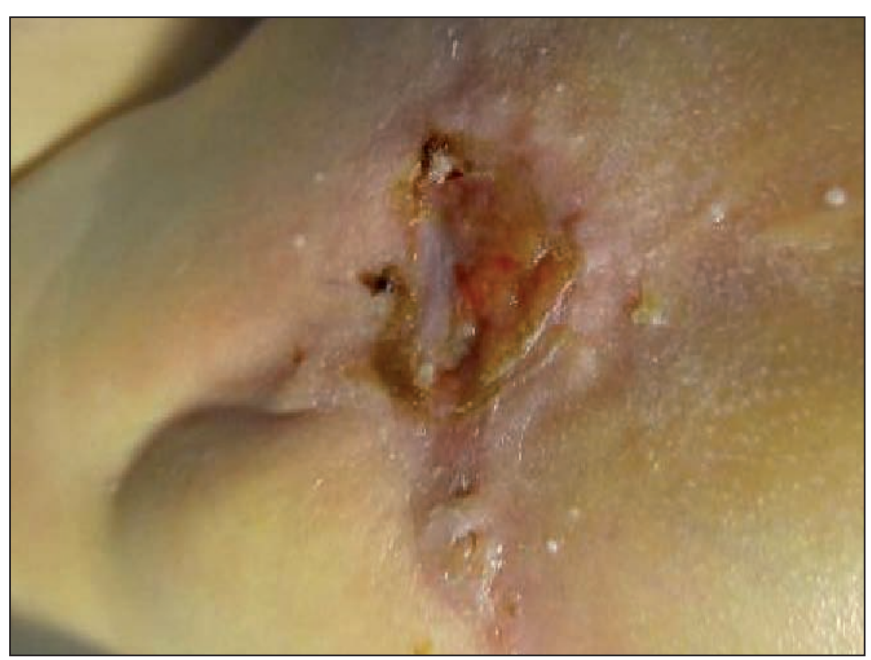

Fig. 6. Cierre completo de la fístula y epitelización de la dehiscencia.

El paciente sufrió complicaciones de su enfermedad de base y precisó nueva intervención quirúrgica por obstrucción intestinal. En el momento de escribir este artículo, el paciente sigue ingresado con estado grave.

\section{Caso 5.}

Terapia de vacío en heridas complejas en miembros inferiores tras accidente de tráfico

Varón de 10 años de edad que acude a Urgencias tras sufrir accidente de tráfico presentando pérdida de sustancia de aproximadamente $20 \times 20 \mathrm{~cm}$ en superficie lateral de pierna derecha y de $15 \times 8 \mathrm{~cm}$ en dorso de pie derecho con exposición de tendones extensores $2^{\circ}$ y $3^{\circ}$.

Se realiza desbridamiento de tejido no viable, extracción de cuerpos extraños y cura con Acticoat ${ }^{\circledR}$ e Intrasite ${ }^{\circledR}$ (Fig. 7). A la semana del accidente, tras varias curas y limpieza de las heridas, procedemos a la aplicación de sistema VAC@ con esponja de poliuretano a $-75 \mathrm{mmHg}$ en modo continuo con sistema en Y para cobertura de dorso de pie y de cara lateral de pierna. Realizamos la primera cura a los 4 días (Fig. 8) y a la semana, volvemos a intervenir quirúrgicamente; en esta ocasión realizamos limpieza y cobertura con Integra monolayer ${ }^{\circledR}$ y autoin- 


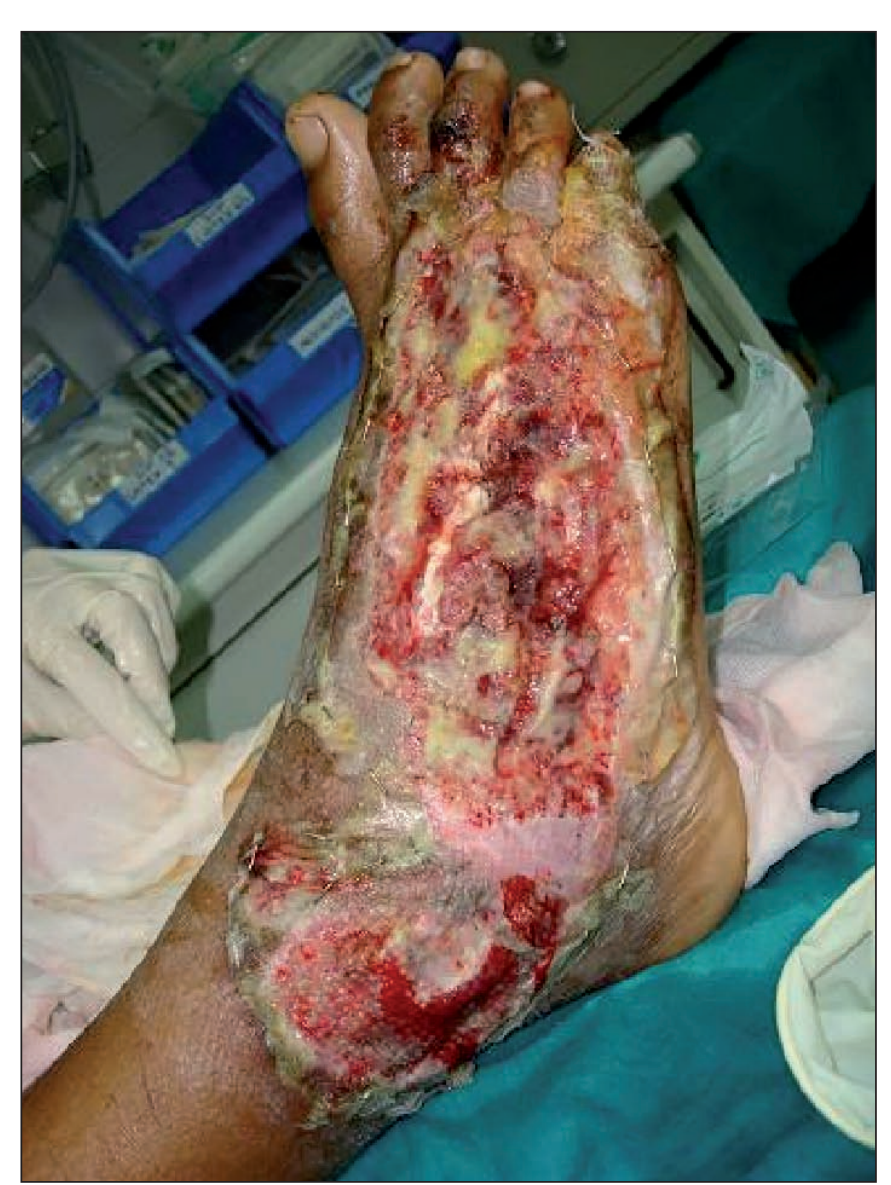

Fig. 7. Aspecto de la herida previo a la colocación del sistema VAC $₫$.

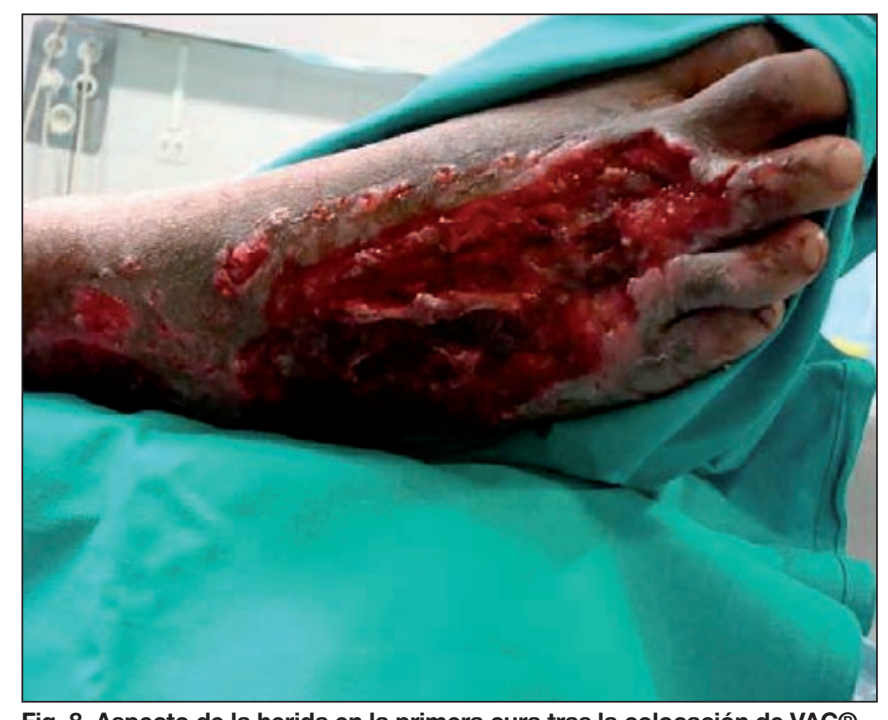

jerto de piel parcial, sobre los cuales colocamos de nuevo el sistema VAC@ con esponja de poliuretano (interponiendo un apósito de vaselina para evitar la adherencia) a $-125 \mathrm{mmHg}$ en modo continuo. A los 5 días, realizamos la primera cura de los injertos comprobando un prendimiento del $95 \%$, por lo que decidimos retirar el sistema VAC®. Como dato a resaltar, en la primera cura del sistema VAC® se realizó cultivo de la herida que fue positivo para Pseudomonas aeruginosa y se inició tratamiento con Ciprofloxacino; en la siguiente cura, se volvió a tomar cultivo que en este caso fue negativo.
A la semana de la retirado el sistema VAC®, realizamos la segunda cura de los injertos observando pérdida del $25 \%$ de los mismos, lo que nos hizo sospechar sobreinfección pese a que el cultivo fuera negativo. El paciente precisó nuevo autoinjerto de piel para conseguir cobertura definitiva, logrando curación completa a las 5 semanas de la retirada de la terapia de vacío. En el momento de escribir este artículo, el paciente está pendiente de una nueva intervención quirúrgica para resolver una retracción del tercer dedo del pie (Fig. 9).

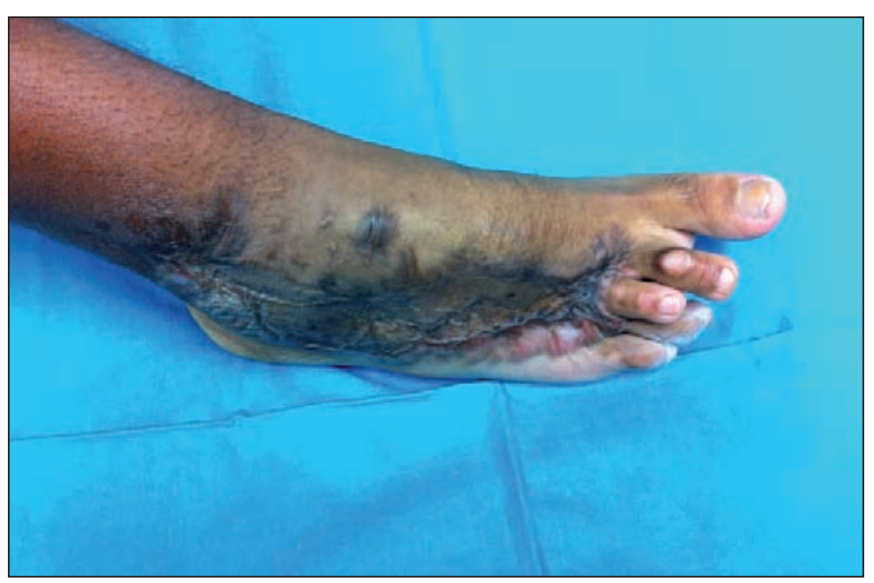

Fig. 9. Aspecto postoperatorio a los 11 meses. Retracción del tercer dedo.

\section{Caso 6.}

Terapia de vacío en dermoabrasiones profundas y heridas disecantes de miembros inferiores

Mujer de 13 años de edad, remitida a nuestro Servicio tras sufrir accidente de tráfico y presentando dermoabrasiones profundas en pierna izquierda.

Realizamos limpieza exhaustiva y exploración quirúrgica de las heridas, comprobando que la herida del maleolo externo izquierdo disecaba el plano muscular hasta el tercio medio de la pierna. Procedimos a cura oclusiva con apósito de vaselina y Nitrofurazona. A los 4 días, decidimos instaurar terapia VAC® con esponja de poliuretano a -125 mmHg en modo continuo. Dos días después, es preciso disminuir la presión a $-75 \mathrm{mmHg}$ también en modo continuo porque la paciente refería dolor. A partir de ese momento, realizamos 2 curas quirúrgicas colocando en ambas el sistema VAC® a $-100 \mathrm{mmHg}$ en modo continuo. A los 11 días del ingreso, realizamos cobertura con Integra ${ }^{\circledR}$ de la lesión del dorso de pie y volvemos a colocar el sistema VAC $\AA$ con apósito de vaselina entre la esponja y la lámina de Integra®. Pasados 4 días, observamos prendimiento de Integra ${ }^{\circledR}$ y buen aspecto del resto de las heridas, por lo que retiramos la terapia de vacío. Como procedimiento definitivo, colocamos injertos laminares de piel parcial en las zonas cruentas y sobre la lámina de Integra ${ }^{\circledR}$. A los 5 días de dicha intervención realizamos la primera cura objetivando prendimiento del $100 \%$ de los injertos. 


\section{Caso 7.}

\section{Terapia de vacío en fasciotomía y prótesis de rodilla expuesta}

Varón, de 11 años de edad, remitido a nuestro Servicio por síndrome compartimental en pierna derecha y exposición de prótesis de rodilla derecha. Tenía diagnóstico de osteosarcoma de fémur derecho hecho en abril del 2009 y había sido tratado con quimioterapia previa a la intervención quirúrgica mediante Ifosfamida, Epiadriamician y Metotrexate. En agosto del 2009 se practicó resección quirúrgica tumoral y colocación de prótesis de rodilla; una semana después, aparece dolor muy intenso en pierna derecha y desaparición de la sensibilidad de la misma, necrosis de piel y tejido celular subcutáneo de la región prerrotuliana, momento en el que se consulta a nuestro Servicio.

Dada la sospecha de síndrome compartimental, practicamos revisión en quirófano, realizando fasciotomía bilateral de pierna derecha que confirma el diagnóstico de síndrome compartimental y desbridamiento de la necrosis prerrotuliana. Una semana después, procedemos a realizar desbridamiento de la rótula y de parte del aparato extensor de la rodilla, así como cobertura de la prótesis expuesta con colgajo muscular de gemelo interno.

Volvemos a realizar cura en quirófano a los 5 días y colocamos en la zona de la fasciotomía, apósito de plata y sistema VAC® a -150 mmHg en modo continuo con esponja de poliuretano. Las curas y cambios del sistema de vacío se realizan cada 3 ó 4 días. Coincidiendo con el momento de la segunda cura, realizamos además colgajo muscular de vasto lateral para cobertura de la prótesis de rodilla. En la tercera cura, colocamos Integra ${ }^{\circledR}$ en las heridas de la fasciotomía y, sobre la misma, el sistema VAC®; de este modo colocamos el sistema de vacío con múltiples conexiones, tanto en la rodilla como en la pierna derecha. En la cuarta cura, cambiamos la esponja de poliuretano normal por una esponja de plata, que será la que utilizaremos a partir de ese momento, evitando así la necesidad de colocar el apósito de plata entre la herida y la esponja (Fig. 10 y 11). A las 3 semanas de la colocación de Integra ${ }^{\circledR}$, aplicamos sobre la misma injertos laminares de piel parcial y, sobre ellos, el sistema VAC®. Además, comprobamos que en la zona de prótesis expuesta aparecía un tejido de granulación limpio y únicamente quedaban unos $3 \mathrm{~cm}^{2}$ de exposición, por lo que colocamos esponja tunelizada. A los 4 días realizamos la primera cura de los injertos comprobando un prendimiento del 100\%. Tras 2 curas más, decidimos cubrir la zona de prótesis expuesta con colgajo fasciocutáneo de perforante de bíceps femoral y retirar el sistema VAC®. Se produjo entonces necrosis de la zona distal del colgajo, por lo que procedimos a su desbridamiento y avance. Tras varias curas e injerto de la zona donante (cubierta con Integra ${ }^{\circledR}$ ), conseguimos cobertura total de la prótesis expuesta a las 5 semanas de la realización del colgajo fasciocutáneo (Fig. 12).

Durante todo el proceso, tomamos múltiples cultivos del exudado de la rodilla que fueron todos positivos a En-

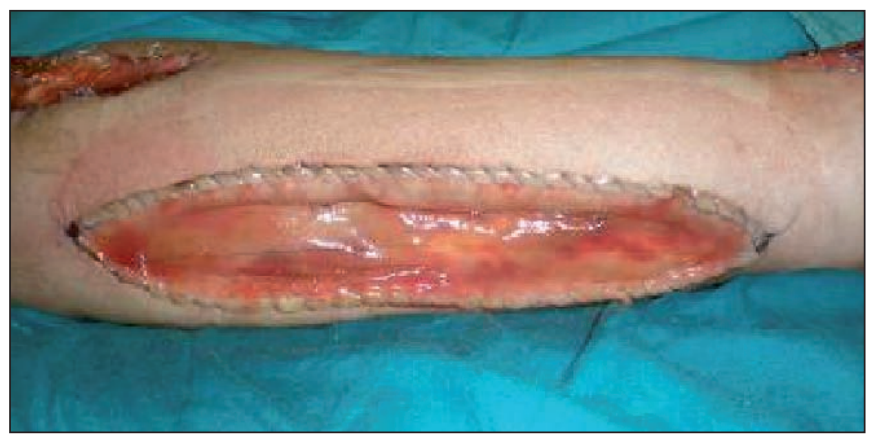

Fig. 10. Integra ${ }^{\circledR}$ sobre heridas de fasciotomía.

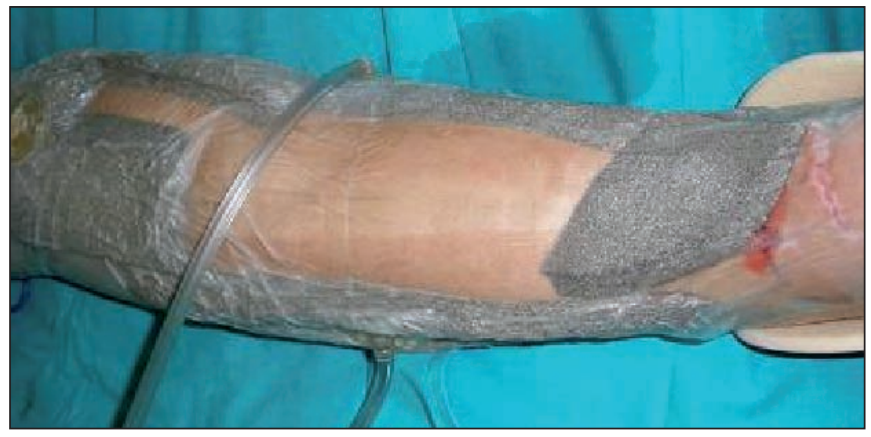

Fig. 11. Sistema VAC $\circledast$ funcionando (esponja de poliuretano con plata).

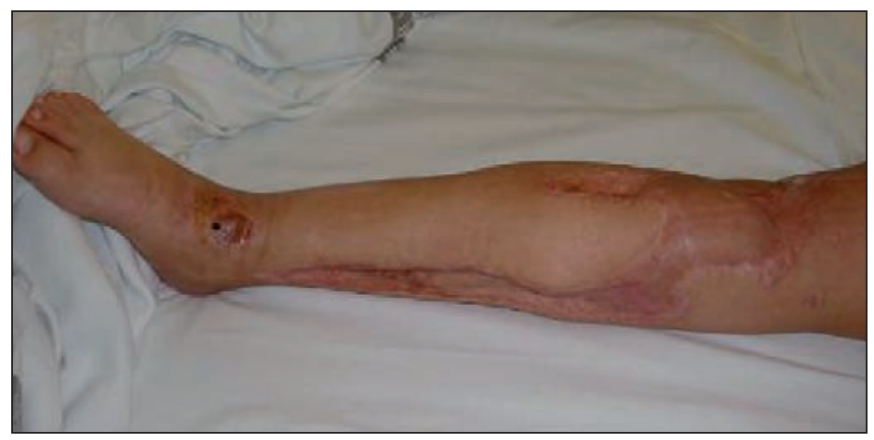

Fig. 12. Resultado final tras curación completa.

terococcus y uno de ellos fue positivo además a Stenotrophomonas maltophilia, ambos microorganismos sensibles a Ciprofloxacino y Fosfomicina, que fue el tratamiento antibiótico pautado al paciente.

\section{Caso 8.}

\section{Terapia de vacío sobre linfangioma de rodilla}

Varón de 9 años de edad que presenta linfangioma en superficie anterior de rodilla izquierda (Fig. 13). Se procede a exéresis del linfangioma y cobertura con Integra ${ }^{\circledR}$ sobre la cual se coloca sistema VAC® a $-100 \mathrm{mmHg}$ en modo continuo con esponja de poliuretano. Realizamos curas cada 3 días (Fig. 14). A las 3 semanas, realizamos injerto laminar de piel parcial y retiramos la terapia de vacío. En la primera cura de los injertos, observamos una sobreinfección de los mismos por lo que tomamos cultivo que resulta positivo para Staphylococcus aureus, por lo que procedemos a curas con pomada antibiótica de Mupirocina. Finalmente, el proceso se resuelve con cicatrización por segunda intención de los restos de injerto perdidos, consiguiendo la epitelización completa a los 15 días. La funcionalidad de la rodilla está conservada (Fig. 15). 


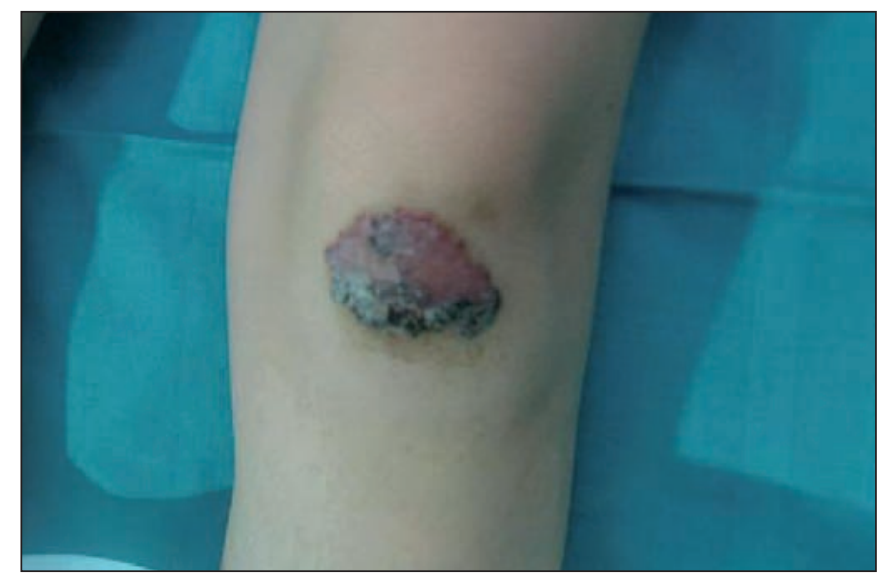

Fig. 13. Linfangioma de rodilla.

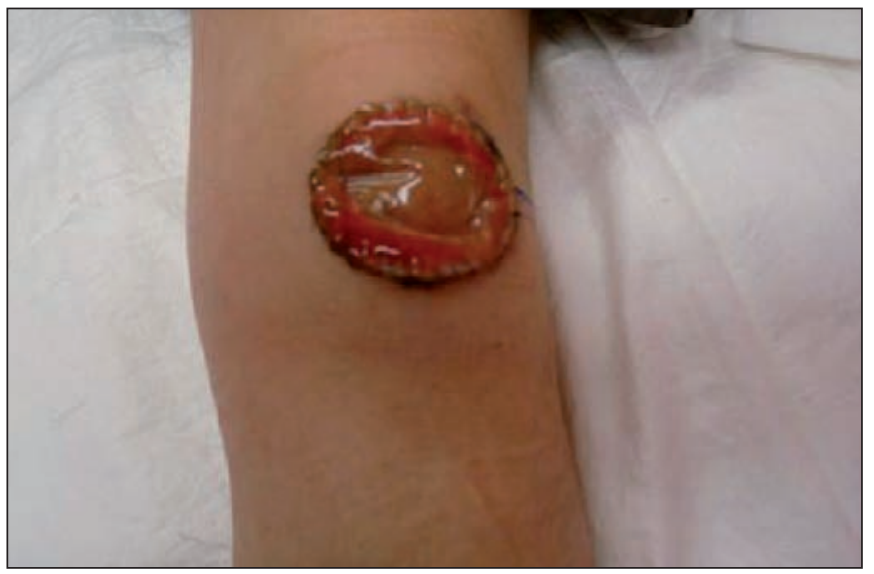

Fig. 14. Aspecto de la lámina de Integra $₫$ tras 2 curas con sistema VAC $₫$.
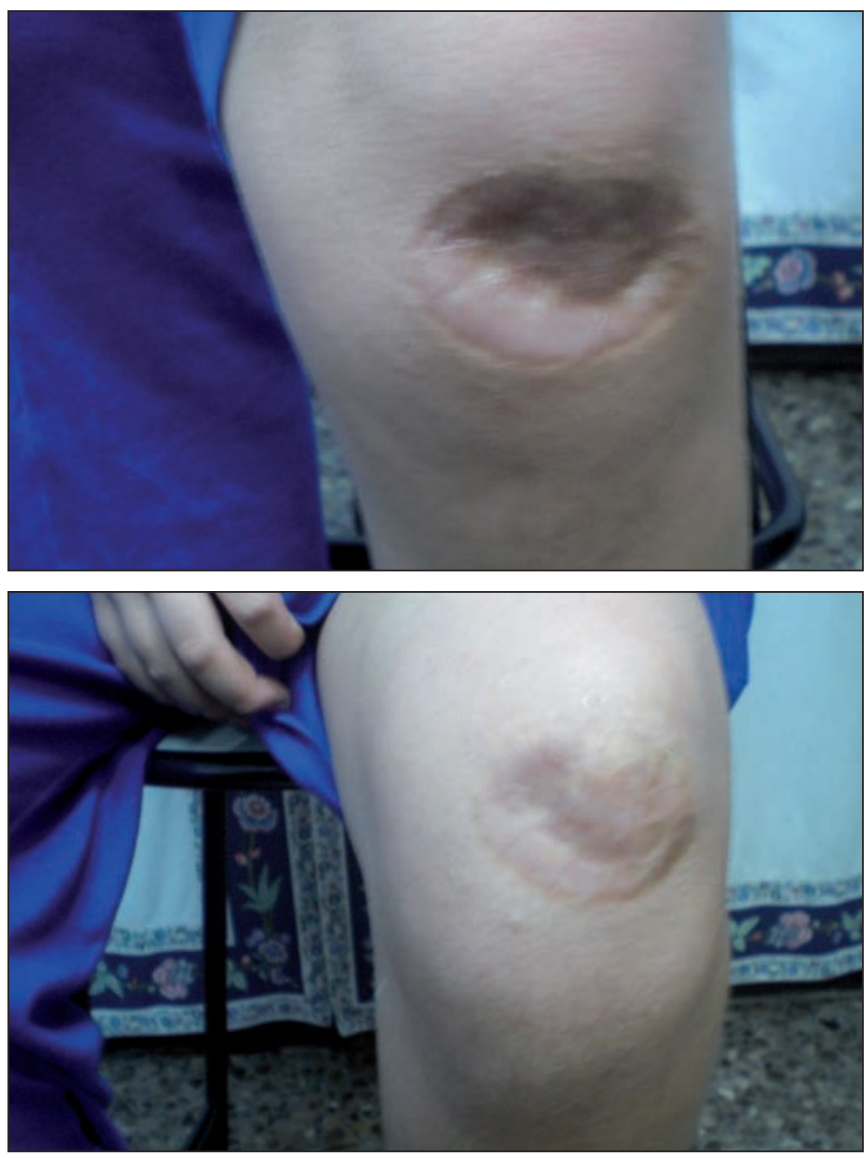

Fig. 15. Aspecto postoperatorio a los 18 meses.

\section{Caso 9. Terapia de vacío en extravasación}

Mujer de 14 años de edad, que presenta extravasación con necrosis en dorso de pie derecho y tetraplejia congénita. Realizamos desbridamiento de los tejidos desvitalizados, quedando expuestos parcialmente los tendones del extensor común de los dedos y del tibial anterior. Colocamos Integra ${ }^{\circledR}$ y sistema VAC $®$ a -125 mmHg en modo continuo con esponja de poliuretano. Realizamos curas 2 veces por semana, observando prendimiento completo y buen aspecto de la dermis artificial. A las 3 semanas, retiramos el sistema VAC@ y procedemos a la cobertura con injerto laminar de piel parcial. A los 5 días, realizamos la primera cura del injerto, observando un prendimiento del $100 \%$.

\section{Caso 10.}

Terapia de vacío en heridas complejas de miembros inferiores

Mujer de 10 años de edad que acude a Urgencias presentando heridas con pérdida de sustancia en pierna izquierda tras sufrir atropello. Realizamos exploración de las heridas en quirófano, observando necrosis de colgajo dermograso de dorso de pie izquierdo (Fig. 16, 17). Después de un desbridamiento exhaustivo, colocamos sistema VAC ${ }^{\circ}$ a $-125 \mathrm{mmHg}$ en modo continuo con esponja de poliuretano que se mantiene durante una semana, realizando curas cada 48h. Con ello, obtuvimos un tejido de granulación sano que permitió, en un segundo tiempo quirúrgico, cobertura con Integra ${ }^{\circledR}$ e injerto laminar de piel parcial a las 3 semanas (Fig. 18). A los 4 días se realiza la primera cura del injerto que se encuentra prendido totalmente (Fig. 19).

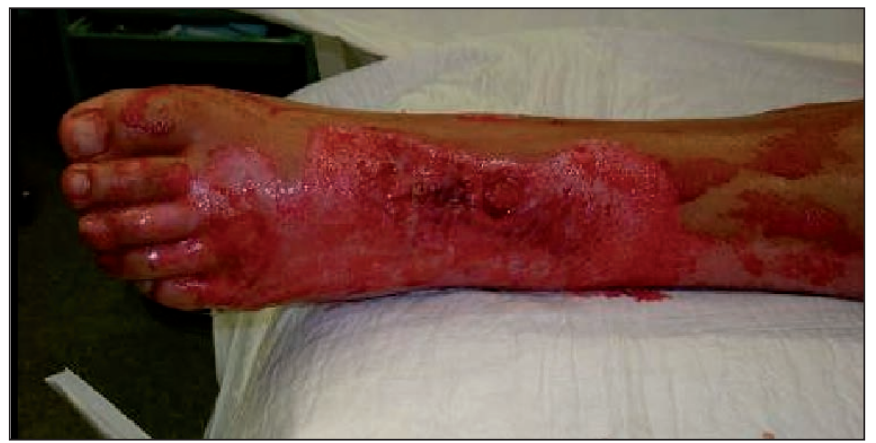

Fig. 16. Aspecto de las heridas a su llegada a Urgencias.

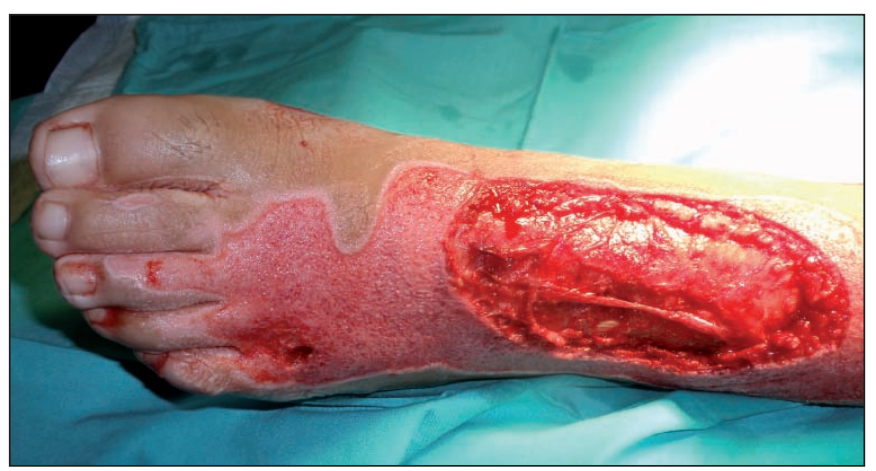

Fig. 17. Aspecto de las heridas en la primera cura tras la aplicación del sistema VAC $\circledast$ (tras el desbridamiento de la necrosis del colgajo dermograso). 


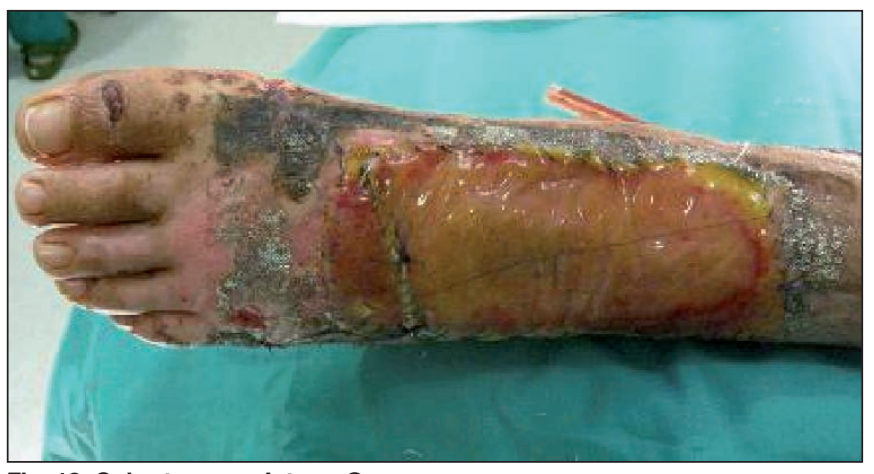

Fig. 18. Cobertura con Integra ${ }^{\circledR}$.

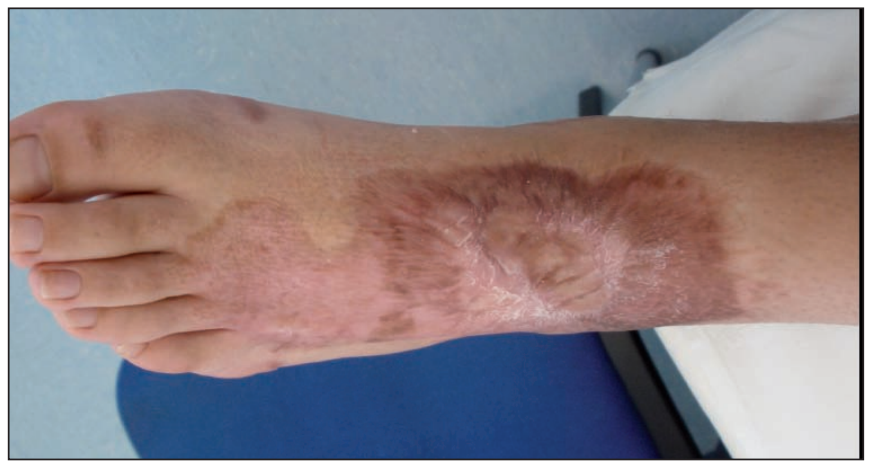

Fig. 19. Aspecto postoperatorio a los 3 años.

\section{Resultados}

Revisamos las historias clínicas de 10 pacientes tratados con terapia de vacío VAC® (KCI Clinic Spain SL) (Tabla I). Del total de pacientes, $50 \%$ son varones y $50 \%$ mujeres. La edad media fue de 6' 8 años (intervalo de 18 días de vida a 14 años). El $70 \%$ (7 de 10 pacientes) corresponde a diferentes patologías en extremidades, el $20 \%$ a dehiscencias de laparotomía y el $10 \%$ a dehiscencias de esternotomía.

La presión media usada durante la terapia fue $-90 \mathrm{mmHg}$ (intervalo de -30 a - $150 \mathrm{mmHg}$ ). En el 100\% de los casos se usó terapia en modo continuo. En el $82 \%$ de los casos se usó esponja de poliuretano VAC Granufoam ${ }^{\circledR}$, en el 9\% esponja de polivinilo VAC Whitefoam ${ }^{\circledR}$ y en el otro $9 \%$ esponja de poliuretano y plata VAC Granufoam Silver®.

El intervalo de curas promedio fue de cada 3' 35 días, con un intervalo de entre 2 y 6 días. El tiempo total medio de mantenimiento de la terapia fue de 17' 6 días, con un intervalo de 4 a 40 días.

Usamos terapia de vacío sobre injertos en un $20 \%$ de los casos y sobre Integra ${ }^{\circledR}$ en un $40 \%$ de los casos.

Los resultados de los cultivos realizados durante el periodo de tratamiento fueron negativos en un $40 \%$ de los casos y positivos en un $60 \%$. Se usó tratamiento antibió-

Tabla I: Pacientes y resultados

\begin{tabular}{|c|c|c|c|c|c|c|c|c|c|}
\hline & EDAD & ETIOLOGÍA & TERAPIA & ESPONJA & $\begin{array}{l}\text { INTERVALO } \\
\text { CURAS }\end{array}$ & \begin{tabular}{|c|} 
TIEMPO \\
TOTAL \\
TRATAMIENTO
\end{tabular} & COBERTURAS & CULTIVOS & ATB \\
\hline CASO 1 & $18 \mathrm{ddv}$ & $\begin{array}{l}\text { DEHISCENCIA } \\
\text { ESTERNOTOMÍA }\end{array}$ & $\begin{array}{l}-75 \mathrm{mmHg} \\
\text { CONTINUA }\end{array}$ & POLIURETANO & C/3 DÍAS & 17 DÍAS & & NEGATIVOS & $\begin{array}{l}\text { VANCOMICINA+ } \\
\text { CEFTAZIDIMA }\end{array}$ \\
\hline CASO 2 & $18 \mathrm{ddv}$ & $\begin{array}{c}\text { TROMBOSIS } \\
\text { ARTERIA ILIACA } \\
\text { + AMPUTACIÓN } \\
\text { FALANGES PIE }\end{array}$ & $\begin{array}{c}-30 \mathrm{mmHg} \\
\text { CONTINUA }\end{array}$ & POLIURETANO & C/2 DÍAS & 4 DÍAS & & POSITIVOS & $\begin{array}{l}\text { VANCOMICINA+ } \\
\text { CEFTAZIDIMA }\end{array}$ \\
\hline CASO 3 & $3 \mathrm{M}$ & $\begin{array}{l}\text { DEHISCENCIA } \\
\text { LAPAROTOMÍA }\end{array}$ & $\begin{array}{c}-50 \mathrm{mmHg} \\
\text { CONTINUA }\end{array}$ & POLIURETANO & C/5 DÍAS & 11 DÍAS & & POSITIVOS & $\begin{array}{c}\text { VANCOMICINA+ } \\
\text { CEFTAZIMIA + } \\
\text { DAKTARIN TÓPICO }\end{array}$ \\
\hline CASO 4 & $4 \mathrm{M}$ & $\begin{array}{l}\text { DEHISCENCIA } \\
\text { LAPAROTOMÍA }\end{array}$ & $\begin{array}{c}-50 \mathrm{mmHg} \\
\text { CONTINUA }\end{array}$ & POLIURETANO & C/3-5 DÍAS & 30 DÍAS & & POSITIVOS & $\begin{array}{l}\text { VANCOMICINA+ } \\
\text { CEFTAZIDIMA }\end{array}$ \\
\hline CASO 5 & $10 \mathrm{~A}$ & $\begin{array}{l}\text { PÉRDIDA } \\
\text { SUSTANCIA } \\
\text { PIERNA }\end{array}$ & $\begin{array}{c}-75 \mathrm{mmHg} \\
\text { CONTINUA }\end{array}$ & POLIURETANO & C/4 DÍAS & 12 DÍAS & $\begin{array}{l}\text { INTEGRA MO- } \\
\text { NOLAYER® E } \\
\text { INJERTOS }\end{array}$ & POSITIVOS & CIPROFLOXACINO \\
\hline CASO 6 & $13 \mathrm{~A}$ & $\begin{array}{l}\text { PÉRDIDA } \\
\text { SUSTANCIA } \\
\text { PIERNA }\end{array}$ & $\begin{array}{l}-125 /-100 \\
\text { mmHg } \\
\text { CONTINUA }\end{array}$ & POLIURETANO & C/2-4 DÍAS & 13 DÍAS & & POSITIVOS & CIPROFLOXACINO \\
\hline CASO 7 & $11 \mathrm{~A}$ & $\begin{array}{c}\text { SÍNDROME } \\
\text { COMPARTIMEN- } \\
\text { TAL Y PRÓTESIS } \\
\text { RODILLA } \\
\text { EXPUESTA }\end{array}$ & $\begin{array}{l}-150 \mathrm{mmHg} \\
\text { CONTINUA }\end{array}$ & $\begin{array}{l}\text { POLIURETANO/ } \\
\text { POLIURETANO } \\
\text { + PLATA }\end{array}$ & C/3-6 DÍAS & 40 DÍAS & $\begin{array}{l}\text { INTEGRA® } \\
\text { E INJERTOS }\end{array}$ & POSITIVOS & $\begin{array}{l}\text { CIPROFLOXACINOY } \\
\text { FOSFOMICINA }\end{array}$ \\
\hline CASO 8 & $9 \mathrm{~A}$ & $\begin{array}{l}\text { LINFANGIOMA } \\
\text { RODILLA }\end{array}$ & $\begin{array}{l}-100 \mathrm{mmHg} \\
\text { CONTINUA }\end{array}$ & POLIURETANO & C/3 DÍAS & 21 DÍAS & INTEGRA® & NEGATIVOS & \\
\hline CASO 9 & $14 \mathrm{~A}$ & $\begin{array}{l}\text { EXTRAVASACIÓN } \\
\text { PIE DERECHO }\end{array}$ & $\begin{array}{l}-125 \mathrm{mmHg} \\
\text { CONTINUA }\end{array}$ & POLIURETANO & C/3 DÍAS & 21 DÍAS & INTEGRA® & NEGATIVOS & \\
\hline CASO 10 & $10 \mathrm{~A}$ & $\begin{array}{l}\text { PÉRDIDA } \\
\text { SUSTANCIA } \\
\text { PIERNA }\end{array}$ & $\begin{array}{l}-125 \mathrm{mmHg} \\
\text { CONTINUA }\end{array}$ & POLIURETANO & C/2 DÍAS & 7 DÍAS & & NEGATIVOS & \\
\hline
\end{tabular}


tico en 7 de los 10 casos (uno de éstos presentaba cultivo negativo).

La única complicación destacada durante el tratamiento fue la aparición de dolor en uno de los pacientes que se solucionó con la disminución de la presión aplicada. En otro caso se adelantó una de las curas por pérdida de vacío del sistema.

\section{Discusión}

Aunque el uso de la terapia de vacío en los hospitales infantiles no está muy extendido, es una herramienta que, dentro del Servicio de Cirugía Plástica Infantil se utiliza con cierta frecuencia. Gracias a su mecanismo de acción, podemos hacer uso del sistema VAC® con distintas finalidades (2):

- Favorecer la aparición de un tejido de granulación sano que permita, bien la cicatrización por segunda intención o bien la cobertura del defecto en un segundo tiempo quirúrgico.

- Controlar la pérdida de líquidos a través de las heridas, gracias al control del exudado que ejerce el sistema. Este punto toma mayor importancia en los pacientes de edad pediátrica, sobre todo en los neonatos, en los que la pérdida de líquidos a través de la herida puede poner en peligro la vida por deshidratación. Es por ello que es importante también en este tipo de pacientes controlar la cantidad de exudado ya que se han descrito casos de pérdida de fluidos exacerbada por la terapia de vacío (3).

- Mantener las heridas en un medio limpio, disminuyendo el riesgo de contaminación gracias a la disminución en la frecuencia de curas y en la manipulación de las heridas.

- Mejorar la gestión de los recursos sanitarios, ya que se disminuye la frecuencia de las curas, la necesidad de personal de enfermería y el tiempo de ingreso hospitalario gracias a los sistemas de terapia portátiles.

- Disminuir el edema en los tejidos, favoreciendo una mejor cicatrización de las heridas o un mejor lecho antes de la intervención quirúrgica.

- Mejorar el confort del paciente gracias a la disminución de la frecuencia de las curas, la disminución del dolor y del mal olor (4).

- Permitir una mayor autonomía del paciente gracias a la menor estancia hospitalaria, a los aparatos portátiles, al comienzo temprano de la rehabilitación y a la disminución del tiempo total de tratamiento.

- Favorecer un mayor prendimiento de los injertos y los sustitutos dérmicos como Integra ${ }^{\circledR}$, al favorecer la inmovilización y adherencia de los mismos.

- Favorecer el cierre de dehiscencias de heridas quirúrgicas al producir aproximación de bordes.

- Mejorar la supervivencia y la morbilidad en pacientes con dehiscencia de esternotomía.
- Ayudar al cierre de fístulas enterocutáneas.

La terapia de vacío en Cirugía Plástica Pediátrica puede ser una herramienta muy útil para cualquier herida compleja, sirviendo como puente para una intervención quirúrgica posterior o favoreciendo la cicatrización por segunda intención.

La esternotomía media es un procedimiento habitual en cirugía cardiaca infantil a la hora de tratar patologías cardiacas congénitas. La dehiscencia esternal y la posterior mediastinitis, suelen ser complicaciones graves de este tipo de cirugías que puede poner en serio peligro la vida de los pacientes. La incidencia de este tipo de complicaciones varía del 0'4 al 5\% en la población pediátrica, siendo mucho mayor el porcentaje de mortalidad asociado a la cirugía cardiaca una vez que la complicación se ha establecido (varía del 5 al 46\%) (1,5). El tratamiento, una vez que la complicación se ha instaurado, pasa por un desbridamiento adecuado, limpieza y curas de la herida, tratamiento antibiótico y posterior cobertura con un colgajo vascularizado o mediante cierre directo. La terapia de vacío ha demostrado ser útil como herramienta de tratamiento en este tipo de complicaciones, puesto que favorece el drenaje de la herida y la limpieza de la misma, junto con la aparición de un tejido de granulación sano (1, 5-7). Salazard y col. observaron que tanto la PCR como el exudado purulento disminuían de manera importante en las primeras 72 horas de tratamiento con la terapia de vacío (7), obteniendo buenos resultados en este tipo de casos. McCord y col. llegaron a la conclusión de que la presión a emplear en heridas esternales estaba alrededor de los $-50 \mathrm{mmHg}$ (entre -50 y $-75 \mathrm{mmHg}$ ), siempre en modo continuo. Como ellos, otros autores abogan por el uso de presiones relativamente bajas, generalmente más baja cuanto más pequeño es el paciente $(1,5,6)$, de manera que no se produzcan cambios o alteraciones en la función cardiaca, la presión sanguínea o el patrón respiratorio. Estas constantes deben ser controladas en todo momento, pues en estos pacientes es en ocasiones el único modo de saber si la terapia está siendo dolorosa. En un estudio reciente, Borgquist y col. (8) han demostrado que a medida que aumenta la presión aumenta la contracción de los bordes de la herida y la evacuación de fluidos de la misma. Sin embargo, existe un límite de presión a partir del cual no se consigue beneficio alguno. Estos límites son -75 mmHg para la contracción de la herida y $-125 \mathrm{mmHg}$ para la evacuación de exudado.

En resumen, podríamos decir que en las dehiscencias de esternotomía en pacientes pediátricos, es adecuado el uso de la terapia de vacío con presión baja continua y controlando en todo momento las constantes del paciente. Con ello, hemos conseguido el cierre completo de la herida en el caso que presentamos.

Las heridas abdominales que aparecen en la edad pediátrica pueden tener distinta etiología: defectos congénitos (onfalocele, gastrosquisis), heridas traumáticas, dehiscencias de laparotomía, fístulas enterocutáneas, etc. 
Estos defectos pueden variar tanto en tamaño como en profundidad y el objetivo de su tratamiento así como el tratamiento propiamente dicho, dependerá de estos factores. En la patología congénita, donde generalmente las vísceras aparecen expuestas, el objetivo fundamental será reintroducir el contenido intestinal a la cavidad. Para ello, también se ha utilizado la terapia de vacío (1). Sin embargo, en el caso de las heridas traumáticas o en las dehiscencias, el objetivo de la terapia será conseguir un cierre directo o un lecho adecuado para la posterior cobertura con un injerto, un colgajo u otro procedimiento.

Muchos autores han revisado el tratamiento de dichas heridas llegando a la conclusión de que lo ideal es un adecuado desbridamiento de los tejidos desvitalizados y una cobertura estable. La terapia de vacío tiene cabida en este ámbito como método que favorece la cicatrización, controla el exudado, aproxima los márgenes de la herida, reduce el edema tisular, favorece la granulación y aumenta la perfusión tisular; es por ello que por lo general se consideran una herramienta terapéutica útil, segura y efectiva en este tipo de patología $(1,5,6,9,10)$. En aquellos casos de dehiscencia abdominal y de patología congénita en los que se ha perdido el soporte muscular, suele ser necesaria una reparación más compleja; conviene entonces usar el sistema Abdominal Dressing System ${ }^{\circledR}$. En caso de que la pared muscular permanezca íntegra, el sistema VAC® puede ser una aliado para conseguir el cierre de la herida, disminuyendo así la necesidad de un procedimiento de cobertura más complejo (1).

Las fístulas enterocutáneas aparecen como complicación entre el 0.8 y el $2 \%$ de las intervenciones abdominales. La mortalidad en adultos va del 5 al 37\%, siendo mayor (hasta del 60\%) en el caso de que se trate de fístulas de alto débito o cuando se acompañan de sepsis o malnutrición (1). No existe consenso en cuanto a su tratamiento. Además, los artículos publicados al respecto muestran resultados dispares y no concluyentes en ningún caso; menos aún en la edad pediátrica, donde no hay estudios aleatorizados. Existen algunos autores que presentan varios casos en los que la terapia de vacío ha sido efectiva para el tratamiento de estas fístulas, pero se necesitan estudios con mayor consistencia para corroborar los resultados $(11,12)$. En contraposición a lo anterior, Draus y col. exponen que el uso de la terapia de vacío en el tratamiento de las fístulas es limitado y funciona en pocos casos, siendo el tratamiento idóneo la corrección quirúrgica en el momento adecuado. Es más, hay casos en los que la fístula enterocutánea ha aparecido como complicación del tratamiento con terapia de vacío de una dehiscencia abdominal (9), por lo que debemos ser cautos a la hora de indicar esta terapia en heridas abdominales complejas.

En cualquier caso, podríamos considerar que la terapia de vacío tiene distintos objetivos a la hora de tratar una fístula enterocutánea. En primer lugar, hay que diferenciar si la fístula es aguda o crónica. En el caso de una fístula aguda, la terapia de vacío estará orientada a conseguir un cierre directo de la misma, aunque posteriormente haya que dar una cobertura de mayor calidad al defecto abdominal. En el caso de una fístula crónica, el cierre directo es difícil de conseguir y, entonces, la terapia de vacío persigue la protección de la piel circundante y la consecución de un lecho adecuado para la cobertura posterior (1).

Por otro lado, hay que diferenciar las fístulas según su débito; son fístulas de bajo débito aquellas cuyo exudado es $<200 \mathrm{ml} / 24 \mathrm{~h}$, de débito moderado si está entre 200 y $500 \mathrm{ml} / 24 \mathrm{~h}$ y de alto débito cuando es $>500 \mathrm{ml} / 24 \mathrm{~h}$ $(1,12)$. En el caso de las fístulas de alto débito es más difícil conseguir un cierre completo; por ello, la terapia de vacío nos puede ayudar a estabilizar la fístula y controlar su secreción. En las de moderado o bajo débito, no sólo controla el exudado si no que puede conseguir el cierre completo, como sucedió en el caso que presentamos y en algunos otros casos publicados $(11,12)$.

Las indicaciones de la terapia de vacío en las extremidades inferiores son variadas: heridas traumáticas, quemaduras, fasciotomías, exposición de material de osteosíntesis y estabilización de injertos. Gracias al mecanismo de acción del sistema VAC®, su uso está ampliamente difundido en este tipo de heridas ya que permite una reducción del edema, un aumento de la vascularización local y la aparición de tejido de granulación de mejor calidad (1), todo lo cual contribuye a que disminuya la necesidad de procedimientos complejos para la cobertura de estas heridas (13). Es por todo ello por lo que la terapia de vacío se considera el tratamiento temporal ideal en las heridas de extremidades en la edad pediátrica (1), consiguiendo en algunos casos el cierre completo de las mismas y en otros, un lecho adecuado para su posterior cobertura. Incluso es posible el uso de esta terapia en grandes superficies, como es el caso que presentan Canavese y col. que utilizan la terapia de vacío en ambas extremidades inferiores de una paciente de 8 meses de edad afecta de meningococcemia.

La posibilidad de usar la terapia de vacío con esponja de polivinilo, con menor adherencia, o esponja de poliuretano simple o con plata con la que conseguimos un efecto antimicrobiano, junto con un apósito no adherente, hace que se extienda su uso en heridas en las que hay exposición de tejidos nobles como tendones, ligamentos o incluso nervios (1).

El síndrome compartimental es una complicación que puede amenazar la vida del paciente. Su etiología más frecuente en la edad pediátrica son las fracturas óseas, pero también puede estar producido por daño vascular o por quemaduras circulares (1). El uso de la terapia de vacío en esta patología está ampliamente difundido en el adulto y en menor medida, en los niños. Se ha comprobado que disminuye el edema y facilita el cierre de las incisiones realizadas para descompresión, dando buenos resultados tanto en adultos como en edad pediátrica $(1,9,10)$. 
El uso del sistema VAC ${ }^{\circledR}$ sobre injertos favorece un mayor prendimiento de los mismos ya que asegura una mejor coaptación entre los tejidos con la formación de una fina capa de tejido de granulación, disminuye el edema y el exudado. Es muy útil cuando la superficie a cubrir es irregular, ya que permite una mejor adaptación del injerto al lecho. Además, evita las posibles pérdidas que se puedan producir por cizallamiento o acumulación de exudado o hematomas, que impiden el íntimo contacto entre los planos $(1,2)$. Está comprobada la efectividad del sistema para el prendimiento de injertos sobre colgajos libres, con resultados positivos. De igual modo, parece que el uso de la terapia de vacío sobre Integra ${ }^{\circledR}$ permite una mejor integración de la misma en el receptor, siendo más efectiva la aplicada en modo intermitente, e incluso, que puede acortar el tiempo de maduración de la lámina para su posterior cobertura con injertos (14). En los casos que presentamos, se usó el sistema VAC® sobre Integra® aunque la intención no era realizar una cobertura con injertos en menor tiempo, sino asegurar un buen prendimiento de la misma. El objetivo buscado en los casos en los que se usó sobre injertos fue el mismo. En uno de los casos se usó sobre Integra Single Layer® e injerto realizados en el mismo tiempo quirúrgico; en este paciente, optamos por acortar el tiempo de tratamiento y de estancia hospitalaria ya que el paciente vivía en una región distinta a la del hospital.

En cuanto al uso de la terapia VAC® en los pacientes neonatos, hay poco publicado al respecto. Los estudios son todos retrospectivos o de presentación de casos y con un tamaño de muestra limitado; pero en todos ellos la terapia ha sido efectiva en distintos tipos de heridas y ha permitido un cierre directo de las mismas sin necesidad de intervención quirúrgica (1,4-7,9-11,15). En general, todos los autores coinciden en la necesidad de controlar la pérdida de fluidos en este tipo de pacientes, así como en usar presiones más bajas.

Baharestani y col. presentan en su trabajo (1) una tabla que resume la cifra de presión más adecuada según la edad del paciente y la localización de la lesión en relación a un análisis de múltiples estudios de uso de terapia de vacío en edad pediátrica. En general, en los pacientes menores de 2 años se deben usar presiones entre -50 y $-75 \mathrm{mmHg}$ en cualquier localización; en los pacientes entre 2 y 12 años, las presiones pueden ser mayores. En heridas esternales recomiendan presiones entre -50 y $-75 \mathrm{mmHg}$; en fístulas enterocutáneas, úlceras por presión y quemados, entre -75 y $-125 \mathrm{mmHg}$; en heridas abdominales y enfermedad pilonidal, entre -50 y $-125 \mathrm{mmHg}$ y en el resto, presiones entre -75 y $-100 \mathrm{mmHg}$. Finalmente, para pacientes mayores de 12 años se pueden usar presiones entre -75 y $-125 \mathrm{mmHg}$ en cualquier localización excepto en heridas esternales, en donde recomiendan presiones más bajas (entre -50 y $-75 \mathrm{mmHg}$ ). En este mismo estudio, también realizan una recomendación del tipo de esponja que se debe usar en diferentes heridas. La esponja de poliuretano se puede usar en cualquier tipo de herida y en cualquier edad pero, en heridas esternales, fístulas enterocutáneas y heridas espinales, es preferible el uso de esponja de polivinilo. La esponja de plata puede usarse cuando las heridas presentan signos de infección, pero no recomiendan su uso en heridas abdominales o en fístulas enterocutáneas.

\section{Conclusiones}

La terapia de vacío es una herramienta que ha demostrado ser eficaz en el tratamiento de diferentes tipos de heridas, tanto en la edad adulta como en la pediátrica. Puede ayudarnos a conseguir un cierre directo de heridas de distinta entidad o bien servirnos como tratamiento o cobertura temporal.

Es imprescindible un enfoque adecuado de los distintos tipos de heridas y la elección del mejor tratamiento para las mismas, siendo fundamental el desbridamiento y la limpieza adecuados antes de instaurar la terapia de vacío, que deber ser usada, en general, a menor presión en los pacientes de edad pediátrica que en los de adultos.

El uso de la terapia de vacío en los pacientes pediátricos permite reducir el número de intervenciones quirúrgicas necesarias, así como el tiempo hasta la cobertura definitiva o la curación total, con lo que disminuye la morbimortalidad asociada a estos procesos. Además, combinada con sustitutivos dérmicos o injertos, permite un mayor control de las pérdidas de fluidos y de temperatura a través de las heridas, hecho que disminuye las complicaciones derivadas que pueden ser más graves cuanto más pequeño es el paciente. Por ello, en este tipo de pacientes, debemos controlar en todo momento la cantidad de exudado que se recoge con el sistema así como las constantes del paciente. Además, es una herramienta terapéutica que ha demostrado ser segura en pacientes de cualquier edad, incluyendo los neonatos. Por ello, debemos tenerla en cuenta a la hora de afrontar heridas agudas o crónicas en diferentes localizaciones o de distinta etiología en los pacientes pediátricos.

\section{Dirección del autor}

\author{
Dra. Concepción Lorca García \\ Servicio de Cirugía Plástica y Quemados \\ Hospital Universitario y Politécnico La Fe \\ Bulevar Sur s/n \\ 46026 Valencia. España \\ e-mail: conchi_lg@hotmail.com
}

\section{Bibliografía}

\footnotetext{
1. 1. Baharestani M, Amjad I, Bookout K, Fleck T, Gabriel A, Kaufman D, McCord SS, Moores DC, Olutoye OO, Salazar JD, Song DH, Teich S, Gupta S.: V.A.C.® Therapy in the management of paediatric wounds: clinical review and experience. Int Wound J 2009; 6:1.
} 
2. Orgill DP, Bayer LR.: Update on negative-pressure wound therapy. Plast Reconstr Surg. 2011; 127 Suppl 1:105S.

3. Norton, E., De Souza, B., Marsh, D., Moir, G.: VacuumAssisted Closure (VAC Therapy) and the Risk of Fluid Loss in Acute Trauma. Ann Plast Surg 2006;56: 194.

4. Caniano DA, Ruth B, Teich S.: Wound management with vacuum-assisted closure: experience in 51 pediatric patients. J Pediatr Surg. 2005; 40 (1):128.

5. Dhruti contractor,MA., June Amling, RN., Cinzia Brandoli, P., Laura L., Tosi, MD.: Negative pressure Wound Therapy With Reticulated Open Cell Foam in Children: An Overview. J Orthop Trauma 2008;22:S167.

6. McCord SS, Naik-Mathuria BJ, Murphy KM,McLane KM, Gay AN, Basu CB, Downey CR,Hollier LH, Olutoye OO.: Negative pressure therapy is effective to manage a variety of wounds in infants and children. Wound Repair Regen 2007;15:296.

7. Salazard B, Niddam J, Ghez O, Metras D, Magalon G.: Vacuum-assisted closure in the treatment of poststernotomy mediastinitis in the paediatric patient. J Plast Reconstr Aesthet Surg. 2008;61(3):302.

8. Borgquist O, Ingemansson R, Malmsjö M.: The influence of low and high pressure levels during negative-pressure wound therapy on wound contraction and fluid evacuation. Plast Reconstr Surg. 2011;127(2):551.

9. Baharestani, M.: Use of negative pressure wound therapy in the treatment of neonatal and pediatric wounds: a retrospective examination of clinica. Ostomy Wound Manage, 2007. 53 (6): 75.
10. Gabriel, A., Heinrich, C., Shores, J., Cho, D., Baqai, W., Moores, D., Miles, D., Gupta, S.: Outcomes of vacuum-assisted closure for the treatment of wound in a pediatric population: case series of 58 patients. Surg J. Plast. Reconstr. Aesth. 2009; 62(11):1428.

11. López, G., Clifton-Koeppel, R., Emil, S.: Vacuum-assisted closure for complicated neonatal abdominal wounds. J. Pediatr. Surg., 2008. 43(12):2202.

12. Cro, C., George, KJ., Donnelly, J., Irwin, ST., Gardiner, KR.: Vacuum assisted closure system in the management of enterocutaneous fistulae. Postgrad Med J 2002; 78:364.

13. Shilt JS, Yoder JS, Manuck TA, Jacks L, Rushing J,Paterson SB.: Role of vacuum-assisted closure in the treatment of pediatric lawnmower injuries. $J$ Pediatr Orthop 2004;24:482

14. Baldwin C., Potter M., Clayton E., Izvine L., Dye J.: Topical Negative Pressure Stimulates Endothelial Migrationand ProliferationA Suggested Mechanism for Improved Integration of Integra. Ann Plast Surg 2009;62: 92.

15. Arca MJ, Somers KK, Derks TE, Goldin AB, Aiken JJ, Sato TT, Shilyansky J, Winthrop A, Oldham KT.: Use of vacuum-assisted closure system in the management of complex wounds in the neonate. Pediatr Surg Int. 2005;21(7):532. 